\title{
Sleep duration and subjective psychological well-being in adolescence: a longitudinal study in Switzerland and Norway
}

This article was published in the following Dove Press journal:

Neuropsychiatric Disease and Treatment

3 July 2014

Number of times this article has been viewed

\author{
Nadeem Kalak' \\ Sakari Lemola ${ }^{2}$ \\ Serge Brand ${ }^{1,3}$ \\ Edith Holsboer-Trachsler \\ Alexander Grob ${ }^{2}$ \\ 'Psychiatric Hospital of the \\ University of Basel, Center for \\ Affective, Stress and Sleep Disorders, \\ Basel, Switzerland; ${ }^{2}$ Department of \\ Psychology, ${ }^{3}$ Department of Sport \\ and Health Science, Division of Sport \\ Science, University of Basel, Basel, \\ Switzerland
}

Background: Adolescents' sleep duration and subjective psychological well-being are related. However, few studies have examined the relationship between sleep duration and subjective psychological well-being longitudinally across adolescence - a time of profound biological and psychosocial change. The aim of this longitudinal study was to investigate whether shorter sleep duration in adolescents is predictive of lower subjective psychological well-being 6 months and 12 months later or whether lower subjective psychological well-being is predictive of shorter sleep duration.

Methods: Adolescents (age range, 10.02-15.99 years; mean age, $13.05 \pm 1.49$ years; $51.8 \%$, female) from German-speaking Switzerland $(n=886)$ and Norway $(n=715)$ reported their sleep duration and subjective psychological well-being on school days using self-rating questionnaires at baseline (T1), 6 months (T2), and 12 months from baseline (T3).

Results: Cross-sectional and longitudinal analyses revealed that sleep duration decreased with age. Longer sleep duration was concurrently associated with better subjective psychological well-being. Crossed-lagged autoregressive longitudinal panel analysis showed that sleep duration prospectively predicted subjective psychological well-being while there was no evidence for the reverse relationship.

Conclusion: Sleep duration is predictive of subjective psychological well-being. The findings offer further support for the importance of healthy sleep patterns during adolescence.

Keywords: adolescence, sleep duration, psychological well-being, international, longitudinal study

\section{Introduction}

Complaints about poor sleep and daytime sleepiness are common among adolescents, ${ }^{1,2}$ and acute $^{3}$ and chronic ${ }^{4}$ sleep disturbances have been related to poor psychological functioning, such as impaired cognitive performance, ${ }^{5,6}$ depression, ${ }^{7-12}$ and poor physical health. ${ }^{13-16}$ Short sleep duration, insomnia, as well as interrupted sleep due to sleep apnea, nocturnal enuresis, and periodic limb movement in children and adolescents adversely affects learning, academic performance, ${ }^{17-23}$ emotional processing, ${ }^{24-26}$ and - relatedly - psychological functioning. ${ }^{27-30}$ In a cross-sectional survey with a large population of college students $(n=1,125 ; 17-24$ years old $)$, over $60 \%$ of respondents were categorized as poor-quality sleepers with shorter sleep duration. ${ }^{19}$ Poor sleep quality and sleepiness were independently associated with poor school achievement in children and adolescents. ${ }^{20}$ Remarkably, over $25 \%$ of adolescents report sleep disturbances. $^{7,31-34}$ Cross-sectional ${ }^{19,35}$ and longitudinal studies, eg, ${ }^{36,37}$ have shown
Correspondence: Nadeem Kalak Psychiatric Hospital of the University of Basel, Center for Affective, Stress and Sleep Disorders, Wilhelm Klein-Strasse 27, CH-40I2 Basel, Switzerland

Tel $+4|6| 3255236$

$\mathrm{Fax}+41613255513$

Email nadeem.kalak@upkbs.ch 
that acute and chronic sleep disturbances persist over time, which may compromise adolescents' mental and physical health in the long run.

Although older adolescents of 15-16 years still require approximately 9 hours of sleep on average per night as do younger adolescents of around 10-11 years, ${ }^{38-40}$ a wealth of studies shows that average sleep duration decreases significantly across adolescence. ${ }^{22,41-44}$ Several factors may be responsible for this decrease, including: physical maturation; psychological factors; social factors, such as decreasing supervision by parents and increasing importance of peer relations; and issues related to education and training, involving pressure related to academic achievement, homework, vocational issues, and extracurricular

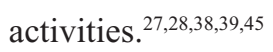

Taken together, the pattern of published evidence suggests that sufficient sleep during adolescence is related to adolescents' psychological well-being. Although there are numerous studies of the relationship between sleep and poor mental health, longitudinal studies focusing on the relationship between sleep duration and positive aspects of functioning, such as psychological well-being, are scarce. ${ }^{46}$ An exception is a 3-year longitudinal study of 2,259 students aged 11-14 years that showed that depressive symptoms and low self-esteem were predicted by short sleep. ${ }^{47}$ Positive psychological well-being involves both cognitive and affective aspects. ${ }^{48}$ Cognitive aspects include evaluations of whether one's life is on the right track and whether one has a positive attitude toward one's future. Affective aspects include whether one experiences positive emotions and joy in life as well as an absence of negative affect and symptoms of mental distress. ${ }^{48}$

The present study extends upon previous research in two respects. First, we studied interrelations between sleep schedules and subjective psychological well-being (SPW) across three time points of measurement testing for both directions of prediction. The measurement points were each separated by 6 months (data were collected in May, November, and again in May). Second, we tested whether associations between sleep duration and SPW are different between age groups. We therefore divided the sample into three age categories: 10-11 year olds; 12-13 year olds; and 14-15 year olds. Sleep duration and SPW were assessed in two large samples of adolescents from Switzerland and Norway. Although both countries are examples of Western cultures, they, for instance, differ markedly with regard to day length in May and November, which may be associated with sleep patterns and SPW. ${ }^{32}$

\section{Methods}

\section{Participants}

In total, 2,703 adolescents provided data on at least one measurement time point. A total of 1,601 adolescents (age range at $\mathrm{T} 1,10.02-15.99$ years; mean age, 13.05-1.49 years; $51.8 \%$ females) from two different European countries (Switzerland, $n=886$; Norway, $n=715$ ), and from a socioeconomically diverse sample provided complete data across all three measurement waves (T1, n=2,330; T2, n=2,094; T3, n=2,061. As data were assessed during school lessons with school classes, it is possible that, for instance, some participants provided no data at $\mathrm{T} 1$ but at a later assessment time). Comparing adolescents with complete data with the ones with incomplete data revealed that participants with complete data were younger $(F[1 ; 2,520]=29.1 ; P<0.001)$, more often female $\left(\chi^{2}[1]=10.23 ; P=0.001\right)$, had higher levels of SPW at T1 $(F[1 ; 2,363]=23.55 ; P<0.001)$, and at T2 $(F[1 ; 2,139]=17.80 ; P<0.001)$, as well as longer sleep duration at $\mathrm{T} 1(F[1 ; 2,340]=116.04 ; P<0.001)$. The two nations did not differ with regard to the probability of having complete data $\left(\chi^{2}[1]=0.22 ; P=0.88\right)$. Furthermore, the two national groups differed with respect to age $(\mathrm{F}[1$; $2520]=37.65 ; P<0.001)$; the Swiss sample mean age was $13.34 \pm 1.54$ years; the Norwegian sample mean age was $12.97 \pm 1.50$ years). Sex distribution was not significant $\left(\chi^{2}[1]=0.16 ; P=0.69\right)$. The grades sampled were from fourth to ninth; these school years are compulsory in both countries. Socioeconomic status was: 31\%, upper class; $37 \%$, middle class; and $32 \%$, working class. The majority of adolescents lived with both parents $(n=2,132 ; 80 \%)$, $18 \%(n=480)$ with their mothers only, and just $2 \%(n=53)$ with their fathers only.

\section{Procedure}

Participants were recruited by advertisements in the local schools in the canton of Bern, located in the Germanspeaking part of Switzerland, and in Bergen (Norway). The first wave of the investigation took place in early summer (May, T1), followed by further waves after 6 months in early winter (November, T2), and again 6 months later in early summer (May, T3). Each assessment took place in the classroom during a school lesson. All participants and their parents gave informed consent regarding study participation. The study followed the ethical principles required by the home institution of the study (the University of Bern, Switzerland) and laid down in the Declaration of Helsinki and was financially supported by the Swiss National Science 
Foundation (Nationales Forschungsprogramm 33 [NFP-33]; project number, 4033-35779).

\section{Materials}

Self-assessment of SPW; Bern well-being questionnaire for adolescents

The present study used five items from the Bern well-being questionnaire for adolescents (BFW/J)-subscale. One item was: "Positive attitude towards life", such as "My future looks good", and "I enjoy life more than most of the other people". Four items from the BFW/J-subscale included: "Joy in life", such as "Did it occur in the past few weeks that you were pleased because you had achieved something?" or "Did it occur in the past few weeks that you were pleased because other people liked you?" Answers were given on four-point rating scales with $1=$ "not at all" and $4=$ "completely". To increase reliability, the nine items were combined to build a score of subjective psychological well-being. Cronbach's alpha of this score was 0.77 at T1, 0.81 at $\mathrm{T} 2$, and 0.82 at T3, which represents good internal consistency.

\section{Sleep duration on weekdays}

Sleep duration on weekdays was assessed with two items asking for time in bed before school days and time of getting up on school days. The participants had to fill in the respective clock times. Sleep duration was calculated by the difference between bed and getting up time.

\section{Statistical analysis}

To assess relationships between sleep duration and SPW in different age groups, we divided participants into three age groups representing very early adolescence: (ages 10-11 years; mean age, $11.20 \pm 0.50$ years); late early adolescence (ages 12 13 years; mean age, $12.96 \pm 0.56$ years); and early middle adolescence (ages $14-15$ years; mean age, $14.94 \pm 0.54$ years).

To compare differences in SPW and sleep duration between countries, age groups, and across the three waves, two analyses of variance (ANOVAs) for repeated measures were computed with the factors country (Switzerland versus Norway), age group ("10 to 11 year olds" versus " 12 to 13 year olds" versus "14 to 15 year olds"), and assessment time (T1, baseline; T2, 6 months from T1; and T3, 12 months from T1). Additionally, Pearson's correlations between sleep duration and SPW were computed separately for the three age groups and the three assessment times. To test longitudinal relations between sleep duration and SPW controlling for the initial levels of these constructs, a crossed-lagged autoregressive longitudinal panel model was employed. This model specifies autoregressive paths (each construct is regressed on its level at the preceding measurement wave), crossed-lagged paths (each construct is regressed on the other construct's level at the preceding measurement wave), as well as correlations between the two constructs (or their residuals) on the concurrent measurement wave. This model was estimated separately for the three age groups applying multi-group comparison and the $\chi^{2}$ difference test. For paths that were not significantly different between the three age groups as indicated by the $\chi^{2}$ difference test, the paths were set equal across groups.

An alpha of $P<0.05$ was accepted as a nominal level of significance. All statistical computations were performed with IBM SPSS ${ }^{\circledR}$ (IBM Corporation, Armonk, NY, USA) and AMOS $^{\circledR} 19$ for Windows (Amos Development Corporation, Spring House, PA, USA). Missing values were not imputed for analyses conducted with SPSS ${ }^{\circledR}$ (ANOVA for repeated measures, correlations), while analyses conducted with the AMOS $^{\circledR}$ applied estimation of missing values by the full information maximum likelihood method.

\section{Results \\ Descriptive statistics for the course of sleep duration and SPW across adolescence}

There were no significant differences between males and females in SPW $(F[d f=1]=3.65 ; P=0.06)$ or sleep duration $(F[d f=1]=0.66 ; P=0.42)$. Repeated measures ANOVA revealed that sleep duration decreased with age in crosssectional analysis (ie, analyses comparing the age groups; $[F\{2 ; 1,584\}=532.23 ; P<0.001])$ and longitudinal analysis (analysis of the trend across the measurement points; $[F\{2$; $1,583\}=276.07 ; P<0.0010])$. Sleep duration was shorter in Norway than in Switzerland $(F[1 ; 1,584]=39.94 ; P<0.001)$. Age-group $\mathrm{X}$ measurement time, country $\mathrm{X}$ measurement time, country $\mathrm{X}$ age group interactions, and the three-way interaction country $\mathrm{X}$ age-group $\mathrm{X}$ measurement time were not significant $(P>0.10)$. Table 1 provides descriptive statistics for sleep duration by countries (Switzerland and Norway), age groups ("10-11 year olds", "12-13 year olds", and "14-15 year olds"), and across the three measurement points ( $\mathrm{T} 1, \mathrm{~T} 2$, and $\mathrm{T} 3)$. The decline in sleep duration across adolescence is reflected by a decline from 10.00 hours and 9.82 hours among the 10-11 year olds at T1 in Switzerland and Norway, respectively, while the 14-15 year olds slept 8.36 hours and 8.01 hours at T3 in Switzerland and Norway. Inspection of effect sizes of the decline in sleep 


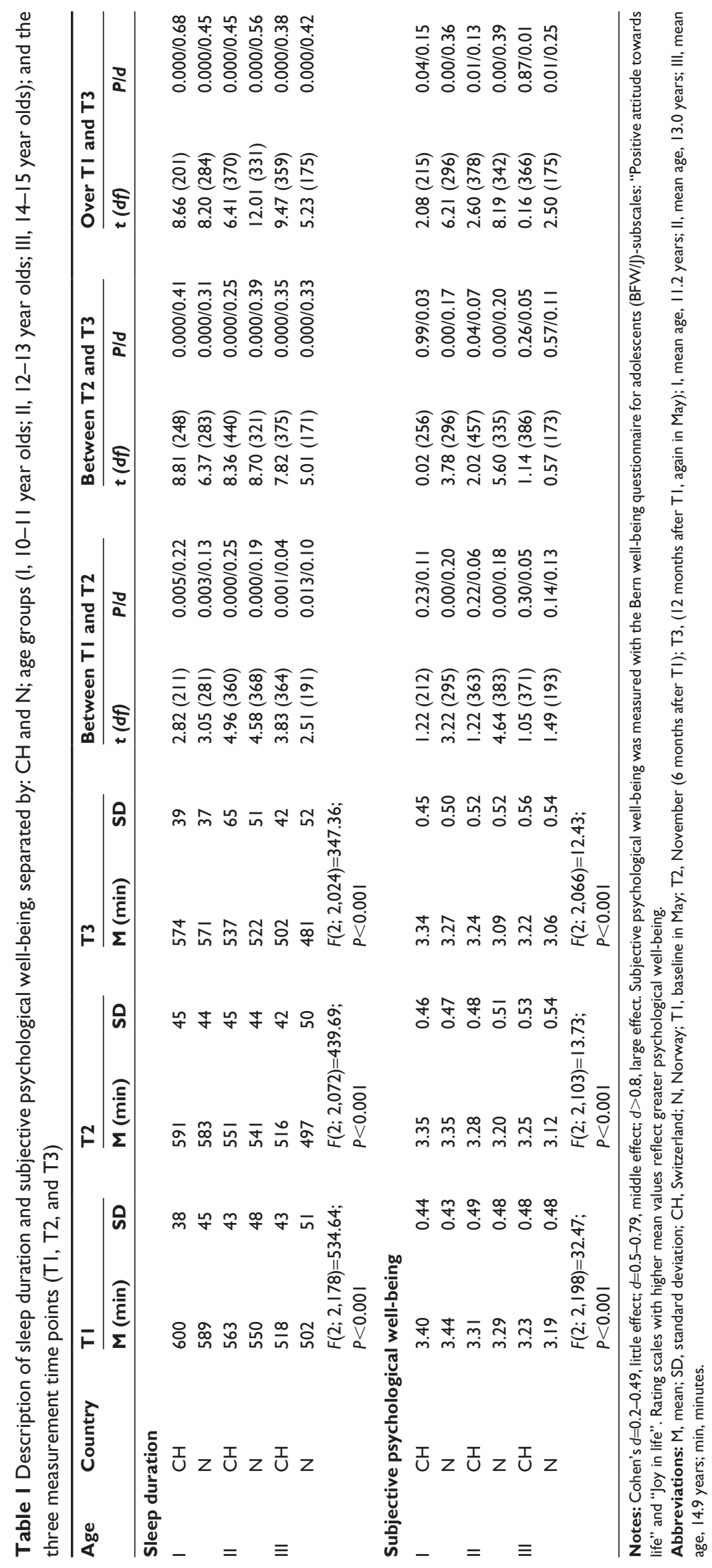


duration in both countries and all age groups indicated a considerably stronger decrease (ie, double the size or more) in the period from November-May than in the period from May-November (with the exception of the 12-13 year olds in Switzerland).

SPW also decreased with age in cross-sectional $(F[2 ; 1,652]=18.87 ; P<0.001)$ and longitudinal analyses $(F[2 ; 1,652]=39.44 ; P<0.001)$. SPW was lower in Norway than in Switzerland $(F[1 ; 1,652]=10.93 ; P<0.001)$. Moreover, the age-group $\mathrm{X}$ measurement time interaction was significant $(F[2 ; 1,652]=3.90 ; P=0.02$; indicating a stronger decline among the $12-13$ year olds than in the younger and older age groups), as was the country $\mathrm{X}$ measurement time interaction $(F[2 ; 1,651]=8.47 ; P<0.001$; indicating a stronger decline among Norwegian adolescents) while the country $\mathrm{X}$ age-group interaction and the three-way interaction were not significant $(P>0.10)$.

\section{Analysis of relationship between sleep duration and SPW}

Table 2 gives the zero-order correlations between sleep duration and SPW in the three age groups. Concurrent correlations between sleep duration and SPW were significantly positive indicating higher levels of SPW among adolescents with longer sleep duration with the exception of concurrent correlations among the 10-11 year olds at T1 and among the 14-15 year olds at T3.

The longitudinal path analysis is displayed in Figure 1. The paths could be set equal across the three age groups (indicating similarity of the path coefficients in the three age groups) with the exception of the path from sleep duration at T2 on sleep duration at T3, which could only be set equal between the younger two age groups (fit indices for the model allowing this path to vary between the oldest age group and the two younger groups: $\chi^{2}[23]=28.01$; $P=0.22$, root mean square error of approximation $=0.007$; fit indices for comparison with the model which additionally sets this path equal across all age groups: $\chi^{2}[1]=23.35$; $P<0.001)$. Generally, the stabilities of sleep duration and SPW from T1 to T2 to T3 were high to very high. Among the crossed lagged paths (the paths between the constructs of sleep duration and SPW across time points), only the path from sleep duration at T1 to SPW at T2 was significant indicating a positive relation between sleep duration at T1 and SPW at T2. This path was of equal strength in the three age groups; however, it represents a quite small effect size.

\section{Discussion}

Regarding the relationship between sleep duration and SPW, our findings echo evidence from numerous studies that have confirmed an association between adolescents' sleep duration and subjective psychological well-being. ${ }^{19,35,49-52}$ Our findings indicate that sleep duration is a longitudinal predictor of SPW. The findings show that affect regulation is compromised by short sleep. ${ }^{24}$ However, the size of the effect was weak when SPW at baseline was controlled. Moreover, the effect was not consistent across all measurement time points.

By contrast, our findings do not indicate that SPW is a longitudinal predictor of sleep duration. The pattern of results extends upon previous findings in showing that the relationship between sleep duration and SPW across one year is very similar in the three age groups of very early adolescents (10-11 year olds), late early adolescents (12-13 year olds), and early middle adolescents (14-15 year olds).

Table 2 Correlations between sleep duration and subjective psychological well-being, separated by the three age groups (I, I0-II year olds; II, I2-I3 year olds; III, I4-I5 year olds) and three measurement time points (TI, T2, and T3)

\begin{tabular}{|c|c|c|c|c|c|}
\hline \multirow[t]{2}{*}{ SPW } & & \multirow[t]{2}{*}{ Cronbach's alpha } & \multicolumn{3}{|c|}{ Sleep duration } \\
\hline & & & TI & T2 & T3 \\
\hline \multirow[t]{3}{*}{ I } & TI & 0.73 & 0.05 & 0.07 & 0.04 \\
\hline & $\mathrm{T} 2$ & 0.78 & $0.12 * *$ & $0.11 *$ & $0.09 *$ \\
\hline & T3 & 0.82 & $0.11 *$ & $0.10^{*}$ & $0.10 *$ \\
\hline \multirow[t]{3}{*}{ II } & TI & 0.78 & $0.14 * *$ & $0.09 *$ & $0.10 * *$ \\
\hline & $\mathrm{T} 2$ & 0.80 & $0.12 * *$ & $0.14 * *$ & $0.08^{*}$ \\
\hline & T3 & 0.82 & $0.12 * *$ & $0.09 * *$ & $0.12 * *$ \\
\hline \multirow[t]{3}{*}{ III } & TI & 0.79 & $0.20 * *$ & $0.10 *$ & $0.10 *$ \\
\hline & $\mathrm{T} 2$ & 0.85 & $0.19 * *$ & $0.13^{* *}$ & $0.16 * *$ \\
\hline & $\mathrm{T} 3$ & 0.84 & $0.12 * *$ & $0.09 *$ & 0.06 \\
\hline
\end{tabular}

Notes: $* P<0.05$. $* * P<0.01$. Higher means reflect a more positive SPW.

Abbreviations: TI, baseline in May; T2, in November (6 months after TI); T3, May (I2 months after TI); I, mean age, II.2 years; II, mean age, I3.0 years; III, mean age, I4.9 years; SPW, subjective psychological well-being. 


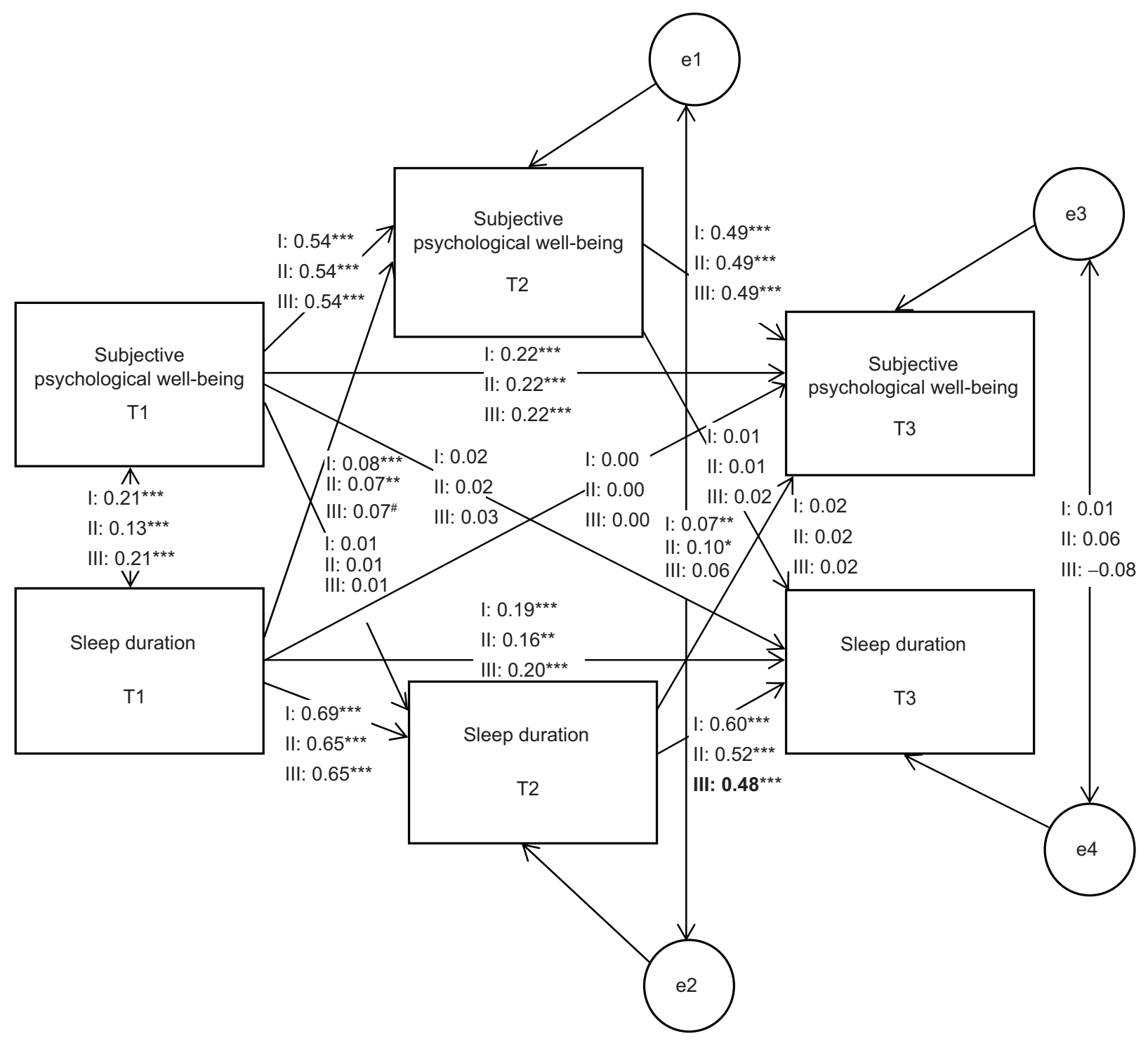

Figure I Longitudinal path model.

Notes: Standardized estimates are displayed. Bold letters indicate that this path is significantly different for the respective age group. Fit indices for the displayed model set all paths equal across age groups, except for the path between sleep duration at T2 and sleep duration at T3 for the oldest age group: $\chi^{2}=28.0 \mathrm{I} ; \mathrm{df}=23$; $P=0.2 \mathrm{I} 5 ; \mathrm{RMSEA}=0.007$. Model comparison of the displayed model with the model setting all paths equal across age groups: $\chi^{2}=23.35 ; d f=I: P<0.00 I$. ${ }^{\# P=0.08 ;} * P<0.05 ; * * P<0.0 I ; * * * P<0.00 I$.

Abbreviations: RMSEA, root mean square error of approximation; I, I0-II year olds; II, I2-13 year olds; III, I4-15 year olds; e, error term.

Regarding changes in sleep duration and SPW across adolescence our findings are consistent with the existing literature by showing that adolescents' sleep duration decreases with age. ${ }^{43,53}$ Interestingly, the reduction in sleep duration was smaller between May (a month with already relatively long day length in the northern hemisphere) and November (a month with relatively short day length in the northern hemisphere) than between November and the following May. This difference might reflect a stronger need for sleep in November than in May possibly due to shorter day length. Sleep duration is associated with seasonal changes in day length; ${ }^{54-59}$ however, we did not find stronger seasonality of sleep duration in Norway than in Switzerland as one might have expected due to the more dramatic seasonal differences in day length in northern countries. While subjective psychological well-being decreased more from May-November than from November-May, this pattern was less pronounced and also inconsistent across subgroups.

Taken together, our findings add to the knowledge that the adolescents' sleep duration plays an important role for their subjective psychological well-being and may inform school counselors on the importance of adequate sleep duration for the adolescents' well-being. We note that, while the 10-13 year old adolescents on average still had the recommended sleep 
duration of 9 hours on weekday nights, ${ }^{40,60}$ sleep duration was on average shorter for the 14-15 year olds although they still require the same amount of sleep as their younger peers. ${ }^{40}$ We believe that both adolescents' and parents' education in sleep hygiene should be promoted, especially for older adolescents, because of their rapid changes in physiology and behavior, ${ }^{61}$ including physical maturation, psychological factors, social factors (eg, parental monitoring decreases from younger adolescence to young adulthood, involvement in peer groups increase with a consequent increase in leisure activities), issues related to vocational development, and extracurricular issues. There is also evidence that favourable parental style as well as parental monitoring of adolescents' bedtimes and stricter household rules with regard to screen time were related to longer sleep and/or better sleep quality, ${ }^{62,63}$ which may in turn play a role for adolescent's psychological well-being. ${ }^{24,63-65}$

\section{Limitations}

The strength of this study is the large sample size that allowed to study three different age groups separately, and its longitudinal design. There are also limitations that preclude overgeneralization of the findings. First, objective measurements (eg, actigraphy) would add to the study, allowing comparisons with subjective measurements. Second, we did not include subjective sleep quality to our analyses. Sleep duration is not necessarily associated with subjective sleep quality, and sleep quality and psychological functioning are associated. ${ }^{66}$ In a related vein, we did not assess other possibly important sleep variables such as sleep debt or circadian preference that would have allowed a more comprehensive picture of adolescents' sleep habits and circadian rhythms. Third, SPW could have been defined and measured differently. More specifically, future research might include additional dimensions of SPW, such as optimism, ${ }^{67}$ satisfaction with life, ${ }^{68}$ and mental toughness. ${ }^{69}$ Fourth, as no measure of depressive disorder was assessed, it was not possible to test whether the associations also hold if participants with clinically relevant depression were excluded. Finally, applying an intervention design to improve sleep would allow to investigate the causal relationship between sleep duration and psychological functioning.

\section{Acknowledgments}

This study was funded by the Swiss National Science Foundation (NFP-33: Nationales Forschungsprogramm 33; project number: 4033-35779). We thank August Flammer, Françoise Alsaker, Walter Herzog, and Wilhelm Felder who acted as principal investigators of the study, and the NFP33 Study Team for data collection and data entry. The study was funded by the Swiss National Science Foundation (principal investigators: August Flammer, Alexander Grob, Françoise Alsaker, Walter Herzog, Wilhelm Felder). We also thank Nick Emler (University of Surrey, UK) for proofreading the manuscript. Finally, we thank the adolescents in Norway and Switzerland as well as their parents for participating in this study and contributing to its success.

\section{Disclosure}

The authors report no conflicts of interest in this work.

\section{References}

1. Heath AC, Eaves LJ, Kirk KM, Martin NG. Effects of lifestyle, personality, symptoms of anxiety and depression, and genetic predisposition on subjective sleep disturbance and sleep pattern. Twin Res. 1998;1(4):176-188.

2. Sateia MJ, Doghramji K, Hauri PJ, Morin CM. Evaluation of chronic insomnia. An American Academy of Sleep Medicine review. Sleep. 2000;23(2):243-308.

3. Kaneita Y, Ohida T, Uchiyama M, et al. The relationship between depression and sleep disturbances: a Japanese nationwide general population survey. J Clin Psychiatry. 2006;67(2):196-203.

4. Roberts RE, Roberts CR, Duong HT. Chronic insomnia and its negative consequences for health and functioning of adolescents: a 12-month prospective study. J Adolesc Health. 2008;42(3):294-302.

5. Meijer AM, Habekothé HT, Van Den Wittenboer GL. Time in bed, quality of sleep and school functioning of children. J Sleep Res. 2000;9(2):145-153.

6. Sadeh A, Gruber R, Raviv A. Sleep, neurobehavioral functioning, and behavior problems in school-age children. Child Dev. 2002;73(2):405-417.

7. Aronen ET, Paavonen EJ, Fjällberg M, Soininen M, Törrönen J. Sleep and psychiatric symptoms in school-age children. J Am Acad Child Adolesc Psychiatry. 2000;39(4):502-508.

8. Cohen-Zion M, Ancoli-Israel S. Sleep in children with attention-deficit hyperactivity disorder (ADHD): a review of naturalistic and stimulant intervention studies. Sleep Med Rev. 2004;8(5):379-402.

9. El-Sheikh M, Buckhalt JA, Mark Cummings E, Keller P. Sleep disruptions and emotional insecurity are pathways of risk for children. $J$ Child Psychol Psychiatry. 2007;48(1):88-96.

10. Gregory AM, O’Connor TG. Sleep problems in childhood: a longitudinal study of developmental change and association with behavioral problems. J Am Acad Child Adolesc Psychiatry. 2002;41(8):964-971.

11. Gregory AM, Eley TC, O’Connor TG, Plomin R. Etiologies of associations between childhood sleep and behavioral problems in a large twin sample. J Am Acad Child Adolesc Psychiatry. 2004;43(6):744-751.

12. Ivanenko A, Crabtree VM, Obrien LM, Gozal D. Sleep complaints and psychiatric symptoms in children evaluated at a pediatric mental health clinic. J Clin Sleep Med. 2006;2(1):42-48.

13. Gangwisch JE, Malaspina D, Boden-Albala B, Heymsfield SB. Inadequate sleep as a risk factor for obesity: analyses of the NHANES I. Sleep. 2005;28(10):1289-1296.

14. Hasler G, Buysse DJ, Klaghofer R, et al. The association between short sleep duration and obesity in young adults: a 13-year prospective study. Sleep. 2004;27(4):661-666.

15. Patel SR, Hu FB. Short sleep duration and weight gain: a systematic review. Obesity (Silver Spring). 2008;16(3):643-653.

16. Vioque J, Torres A, Quiles J. Time spent watching television, sleep duration and obesity in adults living in Valencia, Spain. Int J Obes Relat Metab Disord. 2000;24(12):1683-1688. 
17. Esposito M, Antinolfi L, Gallai B, et al. Executive dysfunction in children affected by obstructive sleep apnea syndrome: an observational study. Neuropsychiatr Dis Treat. 2013;9:1087-1094.

18. Carotenuto M, Esposito M, Parisi L, et al. Depressive symptoms and childhood sleep apnea syndrome. Neuropsychiatr Dis Treat. 2012;8:369-373.

19. Lund HG, Reider BD, Whiting AB, Prichard JR. Sleep patterns and predictors of disturbed sleep in a large population of college students. $J$ Adolesc Health. 2010;46(2):124-132.

20. Dewald JF, Meijer AM, Oort FJ, Kerkhof GA, Bögels SM. The influence of sleep quality, sleep duration and sleepiness on school performance in children and adolescents: A meta-analytic review. Sleep Med Rev. 2010;14(3):179-189.

21. Curcio G, Ferrara M, De Gennaro L. Sleep loss, learning capacity and academic performance. Sleep Med Rev. 2006;10(5):323-337.

22. Perkinson-Gloor N, Lemola S, Grob A. Sleep duration, positive attitude toward life, and academic achievement: the role of daytime tiredness, behavioral persistence, and school start times. J Adolesc. 2013; 36(2):311-318.

23. Schabus M, Hödlmoser K, Gruber G, et al. Sleep spindle-related activity in the human EEG and its relation to general cognitive and learning abilities. Eur J Neurosci. 2006;23(7):1738-1746.

24. Talbot LS, McGlinchey EL, Kaplan KA, Dahl RE, Harvey AG. Sleep deprivation in adolescents and adults: changes in affect. Emotion. 2010;10(6):831-841.

25. Walker MP, van der Helm E. Overnight therapy? The role of sleep in emotional brain processing. Psychol Bull. 2009;135(5):731-748.

26. Dahl RE, Lewin DS. Pathways to adolescent health sleep regulation and behavior. J Adolesc Health. 2002;31(6 Suppl):175-184.

27. Brand S, Kirov R. Sleep and its importance in adolescence and in common adolescent somatic and psychiatric conditions. Int J Gen Med. 2011;4:425-442.

28. Colrain IM, Baker FC. Changes in sleep as a function of adolescent development. Neuropsychol Rev. 2011;21(1):5-21.

29. Jan JE, Reiter RJ, Bax MC, Ribary U, Freeman RD, Wasdell MB. Long-term sleep disturbances in children: a cause of neuronal loss. Eur J Paediatr Neurol. 2010;14(5):380-390.

30. Maret S, Faraguna U, Nelson AB, Cirelli C, Tononi G. Sleep and waking modulate spine turnover in the adolescent mouse cortex. Nat Neurosci. 2011;14(11):1418-1420.

31. Archbold KH, Pituch KJ, Panahi P, Chervin RD. Symptoms of sleep disturbances among children at two general pediatric clinics. J Pediatr. 2002;140(1):97-102.

32. Laberge L, Carrier J, Lespérance P, et al. Sleep and circadian phase characteristics of adolescent and young adult males in a naturalistic summertime condition. Chronobiol Int. 2000;17(4):489-501.

33. Owens JA, Spirito A, McGuinn M, Nobile C. Sleep habits and sleep disturbance in elementary school-aged children. J Dev Behav Pediatr. 2000;21(1):27-36.

34. Paavonen EJ, Aronen ET, Moilanen I, et al. Sleep problems of school-aged children: a complementary view. Acta Paediatr. 2000; 89(2):223-228.

35. Kaneita Y, Ohida T, Osaki Y, et al. Association between mental health status and sleep status among adolescents in Japan: a nationwide crosssectional survey. J Clin Psychiatry. 2007;68(9):1426-1435.

36. Fricke-Oerkermann L, Plück J, Schredl M, et al. Prevalence and course of sleep problems in childhood. Sleep. 2007;30(10):1371-1377.

37. Peter T, Roberts LW, Buzdugan R. Suicidal ideation among Canadian youth: a multivariate analysis. Arch Suicide Res. 2008;12(3): 263-275.

38. Moore M, Meltzer LJ. The sleepy adolescent: causes and consequences of sleepiness in teens. Paediatr Respir Rev. 2008;9(2):114-120; quiz 120.

39. Mercer PW, Merritt SL, Cowell JM. Differences in reported sleep need among adolescents. J Adolesc Health. 1998;23(5):259-263.

40. Carskadon MA, Harvey K, Duke P, Anders TF, Litt IF, Dement WC. Pubertal changes in daytime sleepiness. 1980. Sleep. 2002;25(6): 453-460.
41. Bonnet MH, Arand DL. We are chronically sleep deprived. Sleep. 1995;18(10):908-911.

42. Rajaratnam SM, Arendt J. Health in a 24-h society. Lancet. 2001; 358(9286):999-1005.

43. Iglowstein I, Jenni OG, Molinari L, Largo RH. Sleep duration from infancy to adolescence: reference values and generational trends. Pediatrics. 2003;111(2):302-307.

44. Lemola S, Schwarz B, Siffert A. Interparental conflict and early adolescents' aggression: is irregular sleep a vulnerability factor? J Adolesc. 2012;35(1):97-105.

45. Astill RG, Van der Heijden KB, Van Ijzendoorn MH, Van Someren EJ. Sleep, cognition, and behavioral problems in school-age children: a century of research meta-analyzed. Psychol Bull. 2012;138(6):1109-1138.

46. Wong ML, Lau EY, Wan JH, Cheung SF, Hui CH, Mok DS. The interplay between sleep and mood in predicting academic functioning, physical health and psychological health: a longitudinal study. J Psychosom Res. 2013;74(4):271-277.

47. Fredriksen K, Rhodes J, Reddy R, Way N. Sleepless in Chicago: tracking the effects of adolescent sleep loss during the middle school years. Child Dev. 2004;75(1):84-95.

48. Grob A, Lüthi R, Kaiser F, Flammer A, Mackinnon A, Wearing A. Berner Fragebogen zum Wohlbefinden Jugendlicher (BFW). [The Bern Subjective Well-Being Questionnaire for Adolescents (BFW)]. Diagnostica. 1991;37(1):66-75.

49. Olds T, Blunden S, Petkov J, Forchino F. The relationships between sex, age, geography and time in bed in adolescents: a meta-analysis of data from 23 countries. Sleep Med Rev. 2010;14(6):371-378.

50. Riemann D, Spiegelhalder K, Feige B, et al. The hyperarousal model of insomnia: a review of the concept and its evidence. Sleep Med Rev. 2010;14(1):19-31.

51. Baglioni C, Spiegelhalder K, Lombardo C, Riemann D. Sleep and emotions: a focus on insomnia. Sleep Med Rev. 2010;14(4): 227-238.

52. Haario P, Rahkonen O, Laaksonen M, Lahelma E, Lallukka T. Bidirectional associations between insomnia symptoms and unhealthy behaviours. J Sleep Res. 2013;22(1):89-95.

53. Arbus C, Cochen V. [Sleep changes with aging]. Psychol Neuropsychiatr Vieil. 2010;8(1):7-14. French [with English abstract].

54. Lehnkering H, Siegmund R. Influence of chronotype, season, and sex of subject on sleep behavior of young adults. Chronobiol Int. 2007;24(5):875-888.

55. Thorleifsdottir B, Björnsson JK, Benediktsdottir B, Gislason T, Kristbjarnarson H. Sleep and sleep habits from childhood to young adulthood over a 10-year period. J Psychosom Res. 2002;53(1):529-537.

56. Corbett RW, Middleton B, Arendt J. An hour of bright white light in the early morning improves performance and advances sleep and circadian phase during the Antarctic winter. Neurosci Lett. 2012;525(2):146-151.

57. Wehr TA. The durations of human melatonin secretion and sleep respond to changes in daylength (photoperiod). J Clin Endocrinol Metab. 1991;73(6):1276-1280.

58. Khalsa SB, Jewett ME, Cajochen C, Czeisler CA. A phase response curve to single bright light pulses in human subjects. J Physiol. 2003;549(Pt 3):945-952.

59. Arendt J. Biological rhythms during residence in polar regions. Chronobiol Int. 2012;29(4):379-394.

60. Hense S, Barba G, Pohlabeln H, et al. Factors that influence weekday sleep duration in European children. Sleep. 2011;34(5): 633-639.

61. Spear LP. The adolescent brain and age-related behavioral manifestations. Neurosci Biobehav Rev. 2000;24:417-463.

62. Gangwisch JE, Babiss LA, Malaspina D, Turner JB, Zammit GK, Posner K. Earlier parental set bedtimes as a protective factor against depression and suicidal ideation. Sleep. 2010;33(1):97-106.

63. Short MA, Gradisar M, Wright H, Lack LC, Dohnt H, Carskadon MA. Time for bed: parent-set bedtimes associated with improved sleep and daytime functioning in adolescents. Sleep. 2011;34(6): 797-800. 
64. Kalak N, Gerber M, Kirov R, et al. The relation of objective sleep patterns, depressive symptoms, and sleep disturbances in adolescent children and their parents: a sleep-EEG study with 47 families. J Psychiatr Res. 2012;46(10):1374-1382.

65. Bajoghli H, Alipouri A, Holsboer-Trachsler E, Brand S. Sleep patterns and psychological functioning in families in northeastern Iran; evidence for similarities between adolescent children and their parents. $J$ Adolesc. 2013;36(6):1103-1113.

66. Brand S, Hatzinger M, Beck J, Holsboer-Trachsler E. Perceived parenting styles, personality traits and sleep patterns in adolescents. $J$ Adolesc. 2009;32(5):1189-1207.
67. Lemola S, Räikkönen K, Scheier MF, et al. Sleep quantity, quality and optimism in children. J Sleep Res. 2011;20(1 Pt 1):12-20.

68. Brand S, Beck J, Hatzinger M, Harbaugh A, Ruch W, HolsboerTrachsler E. Associations between satisfaction with life, burnout-related emotional and physical exhaustion, and sleep complaints. World J Biol Psychiatry. 2010;11(5):744-754.

69. Brand S, Gerber M, Kalak N, et al. Adolescents with greater mental toughness show higher sleep efficiency, more deep sleep and fewer awakenings after sleep onset. J Adolesc Health. 2014;54(1):109-113.

\section{Publish your work in this journal}

Neuropsychiatric Disease and Treatment is an international, peerreviewed journal of clinical therapeutics and pharmacology focusing on concise rapid reporting of clinical or pre-clinical studies on a range of neuropsychiatric and neurological disorders. This journal is indexed on PubMed Central, the 'PsycINFO' database and CAS, and is the official journal of The International Neuropsychiatric Association (INA). The manuscript management system is completely online and includes a very quick and fair peer-review system, which is all easy to use. Visit http://www.dovepress.com/testimonials.php to read real quotes from published authors.

Submit your manuscript here: http://www.dovepress.com/neuropsychiatric-disease-and-treatment-journal 